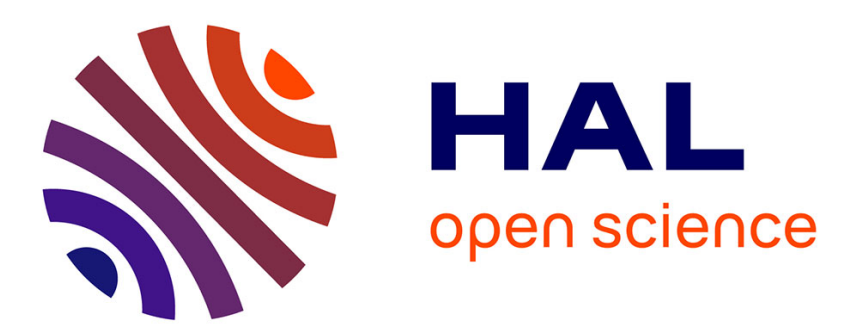

\title{
Statistical and Block Copolymers of Ethylene and Vinyl Acetate via Reversible Addition-Fragmentation Chain Transfer Polymerization
}

\author{
Arne Wolpers, Florian Baffie, Vincent Monteil, Franck d'Agosto
}

\section{To cite this version:}

Arne Wolpers, Florian Baffie, Vincent Monteil, Franck d'Agosto. Statistical and Block Copolymers of Ethylene and Vinyl Acetate via Reversible Addition-Fragmentation Chain Transfer Polymerization. Macromolecular Rapid Communications, 2021, 42 (16), pp.2100270. 10.1002/marc.202100270 . hal03404721

\author{
HAL Id: hal-03404721 \\ https://hal.science/hal-03404721
}

Submitted on 26 Oct 2021

HAL is a multi-disciplinary open access archive for the deposit and dissemination of scientific research documents, whether they are published or not. The documents may come from teaching and research institutions in France or abroad, or from public or private research centers.
L'archive ouverte pluridisciplinaire HAL, est destinée au dépôt et à la diffusion de documents scientifiques de niveau recherche, publiés ou non, émanant des établissements d'enseignement et de recherche français ou étrangers, des laboratoires publics ou privés. 


\title{
Statistical and block copolymers of ethylene and vinyl acetate via RAFT polymerization
}

\author{
A. Wolpers, F. Baffie, V. Monteil,* F. D’Agosto*
}

A dithiocarbamate chain transfer agent (CTA) based on Z-group substituted with a diphenyl amine $\left(-\mathrm{NPh}_{2}\right)$ moiety was selected for the synthesis of statistical and diblock copolymers of ethylene (E) and vinyl acetate (VAc) via reversible addition-fragmentation chain transfer polymerization. Benefiting from the good control chain growth of poly(ethylene) (PE), poly(vinyl acetate) (PVAc), and poly(ethylene-co-vinyl acetate) (EVA) achieved with this CTA, linear diblock copolymers of the type EVA- $b$-PE, EVA- $b$-EVA, and PVAc- $b$-EVA were successfully synthesized. A three-arm EVA star was additionally obtained starting from a trifunctional dithiocarbamate CTA.

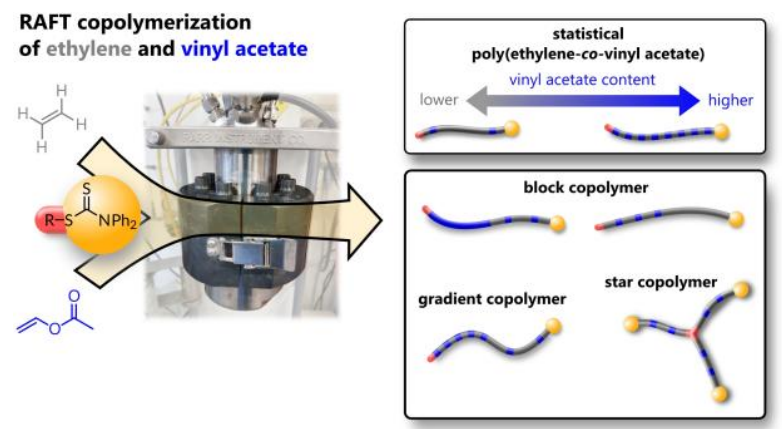

\section{Introduction}

Together with low density polyethylene (PE), copolymers of ethylene (E) and vinyl acetate (VAc) are probably the most important class of copolymers based on E produced industrially by conventional radical polymerization. These poly(ethylene-co-vinyl acetate) (P(E-co-VAc)) can feature a broad range of compositions from very low to high content of VAc and are accordingly called EVA or VAE, respectively. With this variety of products obtained with a single and simple set of inexpensive monomers, namely E and VAc, multiple important applications ${ }^{1-4}$ can be targeted in various areas such as fuel additives, wires, cable insulations 
or foams, adhesives, coatings but also very recently drug delivery or advancing healthcare., Vinyl alcohol-based copolymers are also of industrial interest. They are in majority obtained by hydrolysis of preformed polymers based on VAc. This besides emphasizes the importance of $\mathrm{P}(\mathrm{E}-\mathrm{co}-\mathrm{VAc})$ that can further find applications as gas barriers after hydrolysis. ${ }^{7}$

To achieve these various compositions, copolymerizations of $\mathrm{E}$ and VAc are performed under various conditions either under harsh pressure and temperature conditions $\left(>150{ }^{\circ} \mathrm{C}\right.$ and $>1000$ bar, respectively) but also in bulk, solution or in dispersed media, mostly by aqueous emulsion polymerization in the latter case. ${ }^{8}$ In this context, it is easy to anticipate that strategies that could combine free radical polymerization and the above mentioned processes to produce new architectures including block copolymers based on $\mathrm{P}(\mathrm{E}-\mathrm{co}-\mathrm{VAc})$ segments are of real interest. The design of such architectures however requires mastering reversible deactivation radical copolymerization (RDRcoP) of $\mathrm{E}$ and VAc. $\mathrm{RDRP}^{9}$ is indeed achieved through an equilibrium between propagating radicals and dormant species that is established either via a reversible termination or transfer reaction. One could then argue that the discovery and the advances made in this area over the last 25 years ${ }^{10}$ would have allowed a direct transposition of the available RDRP techniques. However, the peculiar reactivity of E and VAc that can be considered as less activated monomers ${ }^{11,12}$ and the high reactivity of the corresponding propagating radicals made this transposition successful only by focusing on RDRP techniques based on a reversible degenerative chain transfer. This is indeed consistent with the fact that controlled VAc radical homo- and copolymerization is known for many years now and successfully achieved by reversible addition-fragmentation chain transfer (RAFT), ${ }^{13}$ organotellurium mediated radical polymerization (TERP), ${ }^{14,15}$ cobalt-mediated radical polymerization (CoMRP), ${ }^{16}$ iodine transfer polymerization (ITP). ${ }^{17}$ Copolymerization of VAc and E by RDRP was indeed pioneered in 2005 by Sen et al. ${ }^{18}$ Inspired by these works, Jérôme et al. showed in 2007 that the transposition to CoMRP was possible with 
relative success ${ }^{19}$ and the corresponding system was extensively studied by Detrembleur et al. only recently. ${ }^{20}$ The authors fairly mentioned that the homopolymerization of $E$ with the same controlling systems was not achieved. Consistently, as based on optimized control polymerizations of VAc by ITP and CoMRP, these systems rapidly failed at providing the synthetically challenging $\mathrm{P}(\mathrm{E}-\mathrm{co}-\mathrm{VAc})$ with high content of $\mathrm{E}(>60 \%$ of $\mathrm{E})$. This was however not an impediment to already tune the architectures of the obtained VAE for the first time using a RDRP. ${ }^{21-24}$

On our side, we recently postulated that the synthesis of these well-defined copolymers over the range of compositions depicting both EVA and VAE would be possible only with a system that controls the yet unachieved homopolymerization of E. Compared to VAc homopolymerization and copolymerizations of VAc with E, E homopolymerization additionally requires operating conditions compatible with the use of high pressures and for which the inherent irreversible chain transfer reactions are minimized. ${ }^{25}$ Recently, in a study dedicated to the controlled copolymerization of $\mathrm{E}$ and cyclic ketene acetal, ${ }^{24} \mathrm{CoMRP}$ of $\mathrm{E}$ was briefly reported to be controlled without any side reaction at $75^{\circ} \mathrm{C}$ using azobisisobutyronitrile (AIBN) and a $\mathrm{Co}(\mathrm{II})$ chain transfer agent in a ratio 6:1. Control homopolymerizations of $\mathrm{E}$ were indeed achieved for the first time by RAFT using dithiocarbonate $^{12}$ as controlling agents quickly followed by the use of organotelluriummediated radical polymerization (TERP). ${ }^{26}$ Yet, RAFT and TERP systems both suffered from a distinct side reaction of their intermediate radical species. These side reactions could however be strongly reduced via the use of aromatic chain transfer agents. ${ }^{26,27}$ This growing understanding of the underpinning mechanisms that governs the control led us to successfully consider and apply ITP to E as this polymerization technique does not involve intermediate radicals. ${ }^{28}$ Copolymerizations of E and VAc using ITP was also thoroughly investigated and 
as expected allowed not only to produce well-defined EVA and VAE but also block copolymers based on EVA or VAE segments.

In the particular case of RAFT, aromatic dithiocarbamates revealed to be very promising controlling agents for E polymerization. ${ }^{27}$ However, the copolymerization of E and VAc and the design of macromolecular structures based on EVA including block copolymers were not reported. Recently, an analogous study was carried out in the presence cyclic ketene acetal comonomer under however surprising reaction conditions (recipes based on 2 to $4 \mathrm{~mL}$ of reactants in a $100 \mathrm{~mL}$ reactor over $22 \mathrm{~h}) .{ }^{29}$ In the present study, aromatic dithiocarbamates and xanthates (Figure 1) were investigated as chain-transfer agents (CTAs) in the copolymerization of E and VAc. This first screening step allowed to identify a promising CTA that was further used for the design of EVA- $b$-PE, PVAc- $b$-EVA, and EVA- $b$-EVA block copolymers. In addition, a three-arm EVA star was investigated through the use of a CTA carrying three dithiocarbamate moieties.

\section{Experimental}

The experimental setup and conditions used for the homopolymerization of $\mathrm{E}$ are similar to those used in our previous studies ${ }^{12,26,27}$ and are briefly described below. In a general procedure, the radical initiator 2,2'-azobis(2-methylpropionitrile) (AIBN) and the CTA-or macromolecular CTA (macroCTA) in the case of chain extension-were stirred under argon atmosphere in $50 \mathrm{~mL}$ of dimethyl carbonate (DMC) in a $160 \mathrm{~mL}$ autoclave reactor at either $70{ }^{\circ} \mathrm{C}$ or $80^{\circ} \mathrm{C}$ and at a constant $\mathrm{E}$ pressure up to 84 bar. After a predetermined polymerization time, the reactor was cooled down, opened, and the contents were collected with toluene. A similar process was used for copolymerizations of E and VAc, with the only difference that instead of $50 \mathrm{~mL}$ of DMC, a mixture of DMC and VAc with a total volume of

$50 \mathrm{~mL}$ was used. ${ }^{4,12,27}$ Homopolymerizations of VAc were performed in bulk with $8 \mathrm{~mL}$ of 
VAc in a $15 \mathrm{~mL}$ glass vial under argon atmosphere. For all systems, monomer conversion was determined gravimetrically. To measure their molar mass distributions (MMDs), the polymeric products were analyzed by size-exclusion chromatography (SEC). SEC using THF as eluent at $35^{\circ} \mathrm{C}$ and equipped with a refractive-index (RI) and a UV detector was employed for soluble copolymers of E and VAc and for PVAc using a conventional calibration with polystyrene standards or a universal calibration, respectively. For less soluble (co)polymers with a higher E content, SEC using 1,2,4-trichlorobenzene (TCB) as eluent at $150{ }^{\circ} \mathrm{C}$ equipped with an RI detector was carried out using a conventional calibration with PE standards. NMR spectroscopy of the polymeric products was carried out at $90{ }^{\circ} \mathrm{C}$ in benzene$\mathrm{d}_{6} /$ tetrachloroethene in a volume ratio of $1: 2$. The materials used, the experimental setup, the polymerization procedure, and the analytical methods are described in more detail in the Supporting Information.

\section{Results and Discussion}

\section{Selection of a suitable CTA}

In order to find a suitable CTA for block copolymerizations, various xanthates and dithiocarbamates were tested in a screening phase, in which EVAs were produced from RAFT copolymerizations of E and VAc (see Figure 1). It should be noted that the screening was aimed at the rapid identification of the most promising CTAs based on the molar mass characteristics of the obtained copolymers and the consumption of the CTAs, rather than a detailed kinetic analysis of the respective polymerization systems. The pool of CTAs was chosen based on previous work on RAFT polymerizations of E. ${ }^{12,27,30}$ Xanthates and dithiocarbamates are generally suitable CTAs for less activated monomers (LAMs), which include E and VAc, by destabilizing the intermediate radical in the RAFT equilibrium. For the screening, EVAs with number-average molar-mass $\left(M_{\mathrm{n}}\right)$ values between 1500 and $5500 \mathrm{~g} \mathrm{~mol}^{-1}$ with VAc contents between 14 and $18 \mathrm{~mol} \%$ were prepared. The respective 
conditions and results of the polymerization systems involving the different CTAs are described in detail in Tables S1-S2. The EVA chains formed show $M_{\mathrm{n}}$ values in the range of those theoretically expected $\left(M_{\mathrm{n}, \text { theo }}\right)$, with dispersities $(\nexists)$ ranging from 1.5 to 3.9. Although the use of $\mathbf{X} \mathbf{1}$ and $\mathbf{X} \mathbf{2}$ results in EVAs with lower $Ð$ values, the xanthate end-groups undergo significant side reactions which lead to a loss of chain-end functionality during the polymerization. This is an effect that has been equally observed in homopolymerizations of $\mathrm{E}$ and is attributed to the affinity of the intermediate radical to undergo side fragmentation in case of $\mathbf{X} 1^{12,27}$ or cross termination in case of $\mathbf{X 2} .^{27}$ These side reactions have been shown to be much less pronounced or even negligible for dithiocarbamates. ${ }^{27}$ In this respect, it should be noted that the end-group chemistry of PEs is very similar to that of EVAs, as the ultimate monomeric unit is likely to be E rather than VAc even at quite high VAc contents, which will be described in detail later. DTC1 is indeed rapidly consumed at the beginning of the polymerization (Table S2) leading to a fast (re)initiation of new chains. DTC2 is consumed rather slowly and thus (re)initiation of chains is slow. A significantly slower consumption of DTC2 compared to $\mathbf{D T C 1}^{30}$ as well as compared to DTC3, DTC4, and DTC5 ${ }^{27}$ has already been observed in earlier E polymerizations. While DTC3, DTC4, and DTC5 are consumed rapidly, all three CTAs lead to EVAs with significantly broader MMDs than DTC1 (Table S1). Xanthates and dithiocarbamates with aromatic Z-groups, in contrast to xanthates with aliphatic Z-groups, have been shown to cause a more or less pronounced rate retardation of $\mathrm{E}$ polymerizations. ${ }^{27}$ Similar observations were made in the present work for EVAs and all CTAs except X1 lead to rate retardation (Table S1, monomer conversion after $3 \mathrm{~h}$ ), although this effect was not thoroughly investigated here. By far the strongest rate retardation was caused by DTC6 and almost no polymerization was observed even when the concentration of the radical initiator AIBN was doubled compared to the systems of the other CTAs. The fact that DTC6 leads to such a strong retardation that it is practically not usable as a CTA has also 
been observed in E polymerizations. ${ }^{27}$ In conclusion, consistent with our recent findings on the superiority of dithiocarbamate CTAs based on an $\mathrm{NPh}_{2}$ Z-group versus $\mathrm{NPh}(\mathrm{Me})$ in $\mathrm{E}$ homopolymerization, ${ }^{30}$ this preliminary screening study led to consider DTC1 as the most promising CTA for the design of macromolecular structures based on E and VAc.

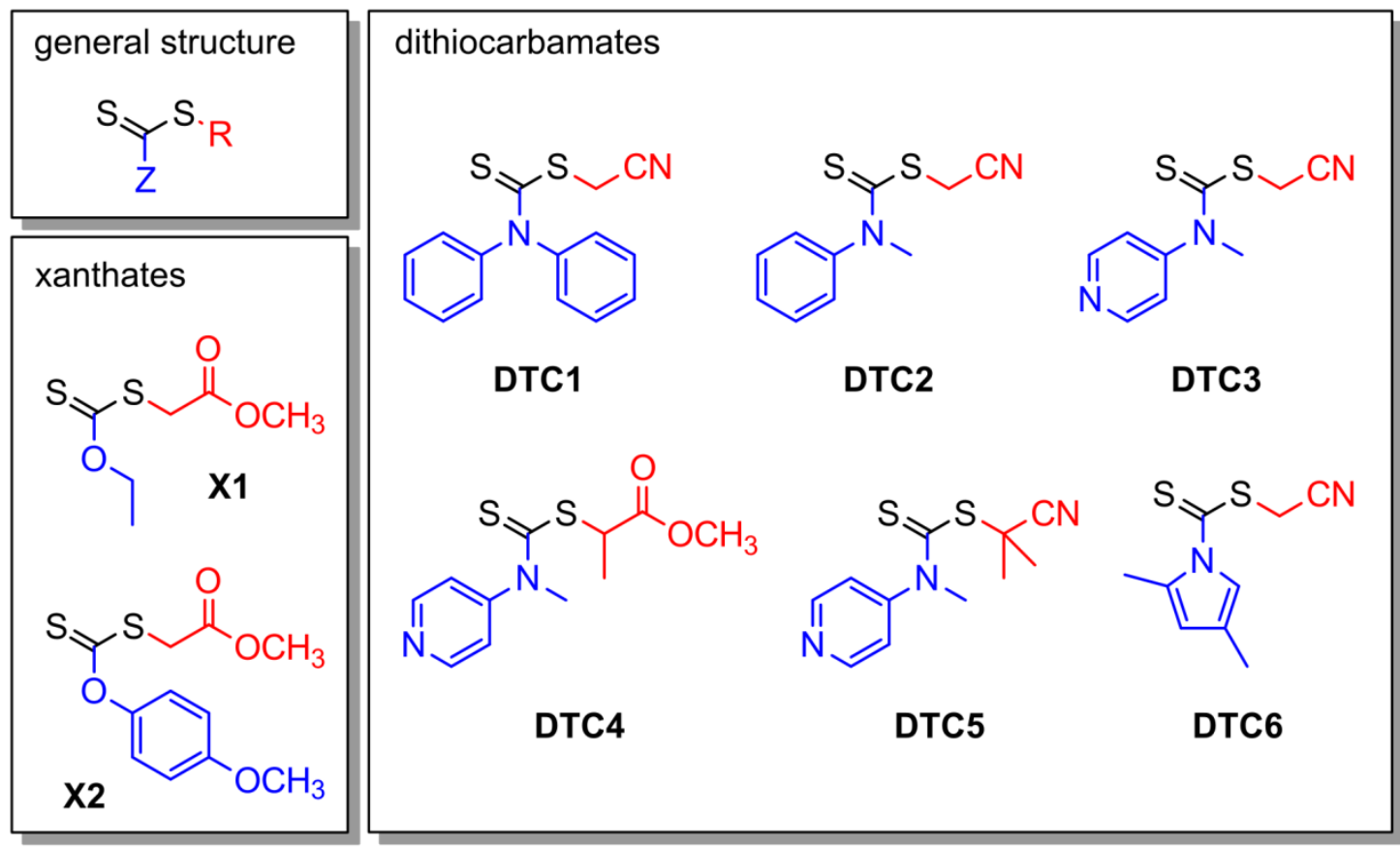

Figure 1. CTAs used in the screening phase to produce EVAs in statistical copolymerizations of E and VAc. X: Xanthate, DTC: dithiocarbamate. R: (re)initiating group, Z: stabilizing group.

\section{Generation of PE, PVAc, and EVA in the presence of DTC1}

In the following, exemplary RAFT systems are presented, which produced PE, PVAc, and EVA in the presence of DTC1. For each system, polymerizations were performed for two different polymerization times (see Table 1). Both PE and EVA were produced in an autoclave at an E pressure of 75 bar in the solvent DMC. PVAc was produced in bulk at ambient pressure in a glass vial. For all three systems, the concentration ratio of DTC1 and the radical initiator $A I B N$ was $[$ DTC1]: $[\mathrm{AIBN}]=3: 1$. More detailed information on the reaction conditions is given in Table 1. All three systems yield polymer with unimodal 
MMDs shifting toward higher molar masses for longer polymerization times (the respective MMDs are presented in the Supporting Information), resulting in increasing $M_{\mathrm{n}}$ values with increasing monomer conversion, as expected in a successful RAFT polymerization. It should be noted that for the EVA particularly prepared in the present work, the exact $M_{\mathrm{n}}$ and $Ð$ values obtained from SEC analyses should be taken with caution. This is because their individual structural properties (i.e., different block lengths, different VAc contents) are likely to lead to different elution behavior during the SEC experiment.

Table 1. Results of three different RAFT polymerization systems with DTC1 producing (i) PE, (ii) PVAc, and (iii) EVA for two different polymerization times each.

\begin{tabular}{lllllll}
\hline entry & $\begin{array}{l}\text { polymer } \\
\text { type }\end{array}$ & $\begin{array}{l}\text { polymerization } \\
\text { time }\end{array}$ & $\begin{array}{l}\text { monomer } \\
\text { conversion } \\
{[\mathrm{g}]}\end{array}$ & $\begin{array}{l}\text { VAc } \\
\text { content } \\
{[\mathrm{mol} \%]^{\mathrm{a}}}\end{array}$ & $\begin{array}{l}\left.M_{\mathrm{n}} \text { [g mol }^{-1}\right](\bigoplus) \\
\text { via SEC }\end{array}$ & $\begin{array}{l}M_{\mathrm{n}, \text { theo }} \\
{\left[\mathrm{g} \mathrm{mol}^{-1}\right]^{\mathrm{c}}}\end{array}$ \\
\hline $1^{\mathrm{d}}$ & $\mathrm{PE}$ & $3 \mathrm{~h}$ & 0.40 & 0 & $1100(1.32)$ & 900 \\
$2^{\mathrm{d}}$ & $"$ & $5 \mathrm{~h}$ & 0.68 & 0 & $1300(1.34)$ & 1400 \\
\hline $3^{\mathrm{e}}$ & PVAc & $2.4 \mathrm{~h}$ & 0.80 & 100 & $1400(1.29)$ & 1400 \\
$4^{\mathrm{e}}$ & $"$ & $4 \mathrm{~h}$ & 3.76 & 100 & $6700(1.43)$ & 5400 \\
\hline $5^{\mathrm{f}}$ & EVA & $1.5 \mathrm{~h}$ & 0.45 & 18 & $3700(2.3)$ & 2800 \\
$6^{\mathrm{f}}$ & $"$ & $3 \mathrm{~h}$ & 1.32 & 17 & $11000(1.88)$ & 7500 \\
\hline
\end{tabular}

${ }^{\mathrm{a}}$ From ${ }^{1} \mathrm{H}$ NMR spectroscopy. ${ }^{\mathrm{b}} \mathrm{In} \mathrm{TCB}$ at $150{ }^{\circ} \mathrm{C}$ for PE, in THF at $35^{\circ} \mathrm{C}$ for PVAc and EVA. ${ }^{\mathrm{c}} M_{\mathrm{n}, \text { theo }}=$ monomer conversion (both E and VAc, in g) $/$ amount of DTC1 (in mol) + MDTC (in $\mathrm{g} \mathrm{mol}^{-1}$ ). ${ }^{\mathrm{d}}$ In an autoclave at $80{ }^{\circ} \mathrm{C}$ : 75 bar of E, $35 \mathrm{mg}$ of AIBN, [DTC1]:[AIBN] $=3: 1$, in $50 \mathrm{~mL}$ of DMC. ${ }^{\mathrm{e}} \mathrm{In}$ a glass vial at $70{ }^{\circ} \mathrm{C}: 8 \mathrm{~mL}$ of VAc, $40 \mathrm{mg}$ of AIBN, [DTC1]:[AIBN] = 3:1, no solvent. ${ }^{\mathrm{f}} \mathrm{In}$ an autoclave at $80^{\circ} \mathrm{C}: 75$ bar of E, $10 \mathrm{~mL}$ of VAc, $10 \mathrm{mg}$ of AIBN, [DTC1]:[AIBN] = 3:1, in $40 \mathrm{~mL}$ of DMC (total volume of $50 \mathrm{~mL}$ ).

Figure 2a shows the ${ }^{1} \mathrm{H}$ NMR spectrum of PE of entry 1 . The spectrum confirms the expected end-capped $\mathrm{PE}$ species. For the $\mathrm{CH}_{2}$ protons adjacent to the $\mathrm{CS}_{2}$ unit, a characteristic triplet $\mathrm{d}$ can be observed at about $3.2 \mathrm{ppm},{ }^{12,27}$ while the signal $\mathrm{b}$ for the protons of the E repeating units is located at about $1.3 \mathrm{ppm}$. Figure $2 \mathrm{~b}$ shows the spectrum of PVAc of entry 3. Again, the expected end-capped polymer species can be observed, with the characteristic $\mathrm{CH}$ signal $\mathrm{m}$ adjacent to the $\mathrm{CS}_{2}$ unit at about $6.8 \mathrm{ppm} .{ }^{31-33}$ The signals of the VAc repeating units are located at $4.9 \mathrm{ppm}(\mathrm{j})$ and from $1.9 \mathrm{ppm}$ to $1.7 \mathrm{ppm}$ (i and $\mathrm{k}$ ). In this context, it should be mentioned that for basically all end-capped chains, the acetate group of the VAc unit is located at the ultimate $\mathrm{C}$ atom next to the $\mathrm{CS}_{2}$ unit, just as in the chemical 
structure depicted in Figure 2b. Alternatively, the acetate group can also be located at the penultimate $\mathrm{C}$ atom, which results in the structure $-\mathrm{CH}\left(\mathrm{OC}(\mathrm{O}) \mathrm{CH}_{3}\right)-\mathrm{CH}_{2}-\mathrm{CS}_{2}$. This leads to a characteristic signal between $3.6 \mathrm{ppm}$ and $3.1 \mathrm{ppm}$ for the $\mathrm{CH}_{2}$ protons ${ }^{34}$ and is a result of the so-called head-to-head addition of VAc with the substituted side of its double bond to the growing macroradical. This species accumulate during RAFT polymerizations due to its low reactivity toward (re)activation compared to the species presented in Figure $2 b^{34,35}$ This effect does not appear to be significant here as the corresponding signals are of very low intensity. Figure 2c shows the spectrum of EVA of entry 5. The expected polymer species can be confirmed. The characteristic signal $\mathrm{w}$ for the $\mathrm{CH}_{2}$ protons adjacent to the $\mathrm{CS}_{2}$ unit is located at $3.2 \mathrm{ppm}$. Similar to the corresponding homopolymers, the signals of the protons of VAc are located at $4.9 \mathrm{ppm}(\mathrm{t})$ and from $1.9 \mathrm{ppm}$ to $1.7 \mathrm{ppm}(\mathrm{s}$ and $\mathrm{u}$ ) and those of $\mathrm{E}$ at $1.3 \mathrm{ppm}(\mathrm{r})$. An interesting aspect is that all chains are end-capped with an ultimate $\mathrm{E}$ unit and there is no signal to indicate an ultimate VAc unit (cf. signal $\mathrm{m}$ at about $6.8 \mathrm{ppm}$ ), even though the EVA has a VAc content of $18 \mathrm{~mol} \%$ after all. This effect is due to the fact that an end-capped chain with an ultimate VAc unit can be (re)activated more easily than one with an ultimate E unit, which makes latter species more stable. ${ }^{12,27}$ For this reason, the end-group chemistry of EVAs is similar to that of PEs. 


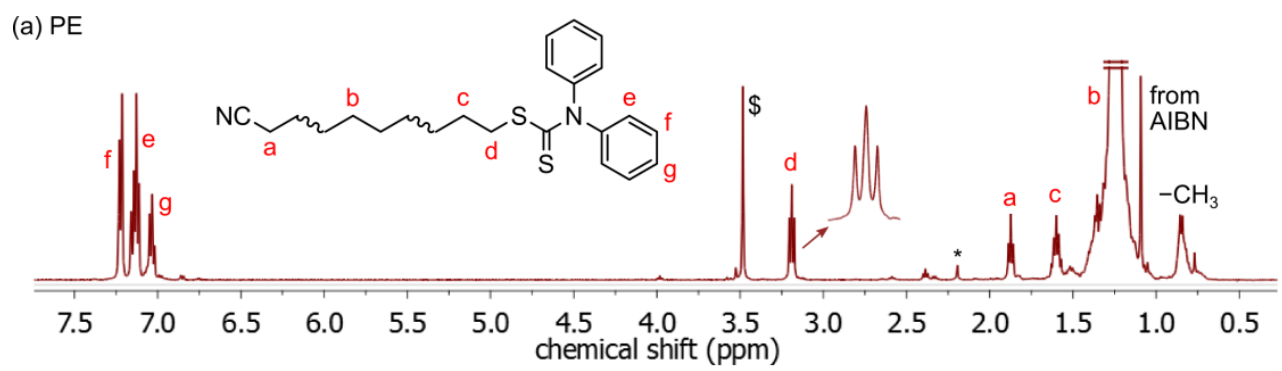

(b) PVAC

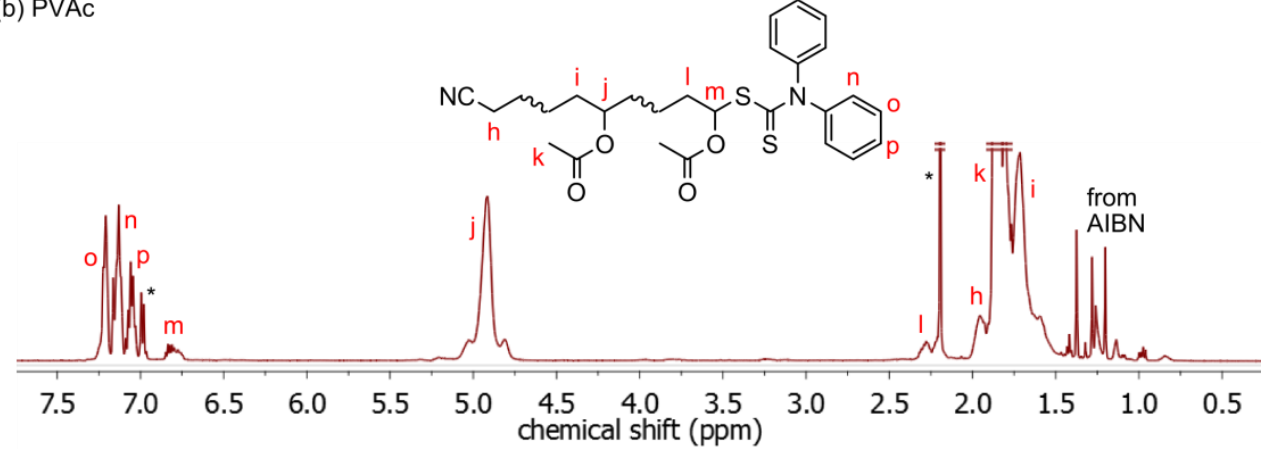

(c) EVA

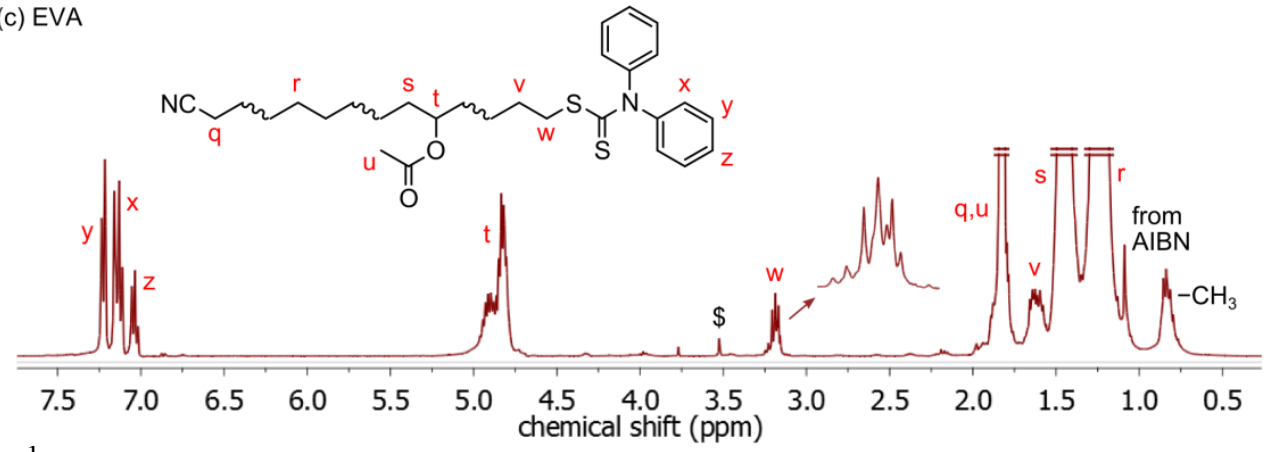

Figure 2. ${ }^{1} \mathrm{H}$ NMR spectra of (a) PE (Table 1, entry 1), (b) PVAc (entry 3), and (c) EVA (entry 5). ${ }^{\$}$ Polymerization solvent DMC, * collecting solvent toluene, $-\mathrm{CH}_{3}$ stems from interand intramolecular chain transfer inherent for radical polymerizations of $\mathrm{E}$, yielding branched polymer chains.

For the $\mathrm{CH}_{2}$ adjacent to the $\mathrm{CS}_{2}$ unit, the same chemical shift of $3.2 \mathrm{ppm}$ is obtained for $\mathrm{PE}$ (signal d) and EVA (signal w). It can be seen, however, that for PE a clean triplet is obtained, while for EVA the signal is somewhat distorted and seems to consist of two or more superimposed triplets. This is due to the fact that even if VAc is not the ultimate monomer unit in the chain, a higher VAc content increases the probability that VAc is the penultimate unit, which slightly influences the shift of the protons of the ultimate E unit. Figure 3 shows ${ }^{1} \mathrm{H}$ NMR signals of the protons corresponding to the said signals $\mathrm{d}$ or $\mathrm{w}$ at $3.2 \mathrm{ppm}$ for PE and EVAs with different VAc contents produced in the presence of DTC1. As the clear trend 
shows, the higher the VAc content of the polymer, the more distorted the signal is. This distortion of the type of signal with the VAc content in EVA was already observed when synthesizing EVA using ITP. ${ }^{28}$ This is indeed a very useful tool to quickly identify if chain extension takes place when block copolymers containing different contents of VAc in the two blocks are targeted (see below). The different VAc contents were obtained by varying the E pressure and/or the VAc volume, and a detailed list of the polymerization conditions and results is included in Table S3. In this respect, it should be noted that the impact of the CTA and thus the RAFT mechanism on the EVAs' VAc content is expected to be minor, if any. Indeed, for the EVA system in Table 1 (entries 5 and 6), copolymer with VAc contents of $18 \mathrm{~mol} \%$ and $17 \mathrm{~mol} \%$ was obtained using an E pressure of 75 bar and a VAc volume of $10 \mathrm{~mL}$, while a comparable conventional polymerization system without CTA yielded an EVA with 16 mol\% of VAc (data not shown).

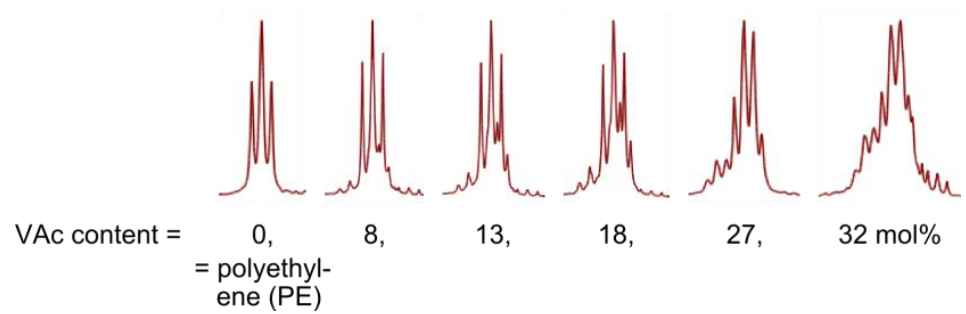

Figure 3. ${ }^{1} \mathrm{H}$ NMR signals at a chemical shift of about $3.2 \mathrm{ppm}$ stemming from the $\mathrm{CH}_{2}$ protons adjacent to the $\mathrm{CS}_{2}$ unit: for PE (Entry 1 in Table S3, cf. signal d in Figure 2a) and EVAs with different VAc contents (Entries 2 to 6 in Table S3, cf. signal w in Figure 2c).

\section{Discussion about the order of block copolymerizations}

In the present work three different types of block copolymers were targeted: EVA- $b-\mathrm{PE}$, PVAc- $b$-EVA, and EVA- $b$-EVA (with EVA blocks of different VAc contents). For each type, the order of the block polymerizations was chosen based on (i) solubility and (ii) chemical reactivity of the first block, which can be considered as macromolecular CTA (macroCTA). (i) PE is only soluble in DMC for very low molar masses of several hundreds of $\mathrm{g} \mathrm{mol}^{-1}{ }^{26}$ The higher the VAc content of the copolymer, the better the copolymer can be 
dissolved in DMC and thus the better its participation as a macroCTA during the polymerization. (ii) The radicals generated from a PVAc macroCTA are mostly secondary, while the radicals generated from either an EVA or PE macroCTA are primary. Secondary radicals show a higher reactivity toward the (re)initiation of the second block and thus a better architectural control than primary ones. The two effects (i) and (ii) lead to the conclusion that as a general strategy, the block with the higher VAc content should be synthesized first, in order PVAc, EVA with a higher VAc content, EVA with a lower VAc content, PE.

\section{EVA-block-PE}

The nomenclature is introduced that EVA22 corresponds to an EVA with 22 mol\% of VAc. An EVA22- $b$-PE block copolymer was synthesized from a chain extension of the macroCTA EVA22 (Table 2, entry 1), which in turn was synthesized in the presence of DTC1 (details on the synthesis of the first block and all other first blocks in Table 2 are presented in the Supporting Information). Figure 4 shows SEC traces of EVA22 and EVA22-b-PE, so before and after chain extension, which show unimodal chain distributions and a clear shift toward higher molar masses. Furthermore, the SEC trace of a PE produced by conventional radical polymerization without macroCTA, but under otherwise identical conditions is also presented in Figure 4. The fact that the trace of PE is at much higher molar masses indicates that the macroCTA is involved in the polymerization and formation of the diblock. In addition, the polymerization rate during chain extension is significantly lower compared to the conventional system ( $0.97 \mathrm{~g}$ versus $2.4 \mathrm{~g}$ of E conversion after $5 \mathrm{~h}$ ), just as is expected for a RAFT polymerization of $\mathrm{E}$ with a CTA containing an aromatic Z-group. ${ }^{27}$ As was already mentioned for EVA and for the same reasons, for the block copolymers of E and VAc, the exact $M_{\mathrm{n}}$ and $Ð$ values obtained from SEC analyses should be taken with caution. However, 
the well-defined chain-ends identified by ${ }^{1} \mathrm{H}$ NMR above allowed us to determine molar masses. As an example, EVA19 used in the chain extension experiments in Table 2 exhibits a $M_{\mathrm{n}}$ of $1580 \mathrm{~g} \mathrm{~mol}^{-1}$ when determined using the chain end ${ }^{1} \mathrm{H}$ NMR signals while the theoretical $M_{\mathrm{n} \text {,theo }}$ was $1600 \mathrm{~g} \mathrm{~mol}^{-1}\left(M_{\mathrm{n}, \mathrm{SEC}}=1900 \mathrm{~g} \mathrm{~mol}^{-1}\right)$. Indeed, a good match is obtained between the values obtained with ${ }^{1} \mathrm{H}$ NMR analyses and the expected ones as shown for EVA- $b$-EVA samples presented in Table 2.

Table 2. Diblock copolymers obtained by chain extension of macroCTAs ${ }^{\mathrm{a}}$ synthesized in the presence of DTC1.

\begin{tabular}{|c|c|c|c|c|c|c|c|}
\hline entry & $\begin{array}{l}\text { polymer } \\
\text { type }\end{array}$ & $\begin{array}{l}\text { first } \\
\text { block/macr } \\
\text { oCTA: } \\
M_{\mathrm{n}}(\bigoplus) \\
\text { mol } \% \\
\mathrm{VAc}^{\mathrm{b}} \\
\end{array}$ & $\begin{array}{l}\text { E pressure; VAc } \\
\text { volume, mass of } \\
\text { AIBN; } \\
\text { polymerizations time }\end{array}$ & $\begin{array}{l}\text { monome } \\
\mathrm{r} \\
\text { conversi } \\
\text { on }\end{array}$ & $\begin{array}{l}\text { diblock: } \\
M_{\mathrm{n}}(\nexists) ;^{\mathrm{c}} \\
\mathrm{mol} \% \mathrm{VAc}^{\mathrm{d}}\end{array}$ & $\begin{array}{l}\text { diblock: } \\
M_{\mathrm{n}}^{\mathrm{e}} / M_{\mathrm{n}, \mathrm{th}} \\
{ }_{\mathrm{eo}}(\mathrm{g} \mathrm{mol} \\
\left.{ }^{1}\right)\end{array}$ & $\begin{array}{l}\text { second } \\
\text { block: } \\
\text { mol\% } \\
\text { VAc }^{f}\end{array}$ \\
\hline 1 & $\begin{array}{l}\text { EVA22-b- } \\
\text { PE }\end{array}$ & $\begin{array}{l}1400 \mathrm{~g} \\
\mathrm{~mol}^{-1} \\
(1.99) ; 22\end{array}$ & 75 bar; -; $34 \mathrm{mg} ; 5 \mathrm{~h}$ & $0.97 \mathrm{~g}$ & $\begin{array}{l}4300 \mathrm{~g} \mathrm{~mol}^{-1} \\
(1.64) ; 6\end{array}$ & $\begin{array}{l}3500 / 27 \\
00\end{array}$ & 0 \\
\hline 2 & $\begin{array}{l}\text { EVA19-b- } \\
\text { EVA11 }\end{array}$ & $\begin{array}{l}1900 \mathrm{~g} \\
\mathrm{~mol}^{-1}(2.2) ; \\
19\end{array}$ & $\begin{array}{l}84 \text { bar; } 7 \mathrm{~mL} ; 10 \mathrm{mg} ; 1 \\
\mathrm{~h}\end{array}$ & $0.41 \mathrm{~g}$ & $\begin{array}{l}6500 \mathrm{~g} \mathrm{~mol}^{-1} \\
(1.73) ; 14\end{array}$ & $\begin{array}{l}4300 / 38 \\
00\end{array}$ & 11 \\
\hline 3 & $\begin{array}{l}\text { EVA19- } b- \\
\text { EVA03 }\end{array}$ & " & $\begin{array}{l}84 \mathrm{bar} ; 3.5 \mathrm{~mL} ; 10 \mathrm{mg} \\
0.5 \mathrm{~h}\end{array}$ & $0.13 \mathrm{~g}$ & $\begin{array}{l}2700 \mathrm{~g} \mathrm{~mol}^{-1} \\
(2.4) ; 12\end{array}$ & $\begin{array}{l}2550 / 23 \\
00\end{array}$ & 3 \\
\hline 4 & $\begin{array}{l}\text { EVA32-b- } \\
\text { EVA10 }\end{array}$ & $\begin{array}{l}1100 \mathrm{~g} \\
\mathrm{~mol}^{-1}(2.1) ; \\
32\end{array}$ & $\begin{array}{l}84 \text { bar; } 7 \mathrm{~mL} ; 15 \mathrm{mg} \\
0.8 \mathrm{~h}\end{array}$ & $0.32 \mathrm{~g}$ & $\begin{array}{l}2900 \mathrm{~g} \mathrm{~mol}^{-1} \\
(2.5) ; 16\end{array}$ & $\begin{array}{l}2750 / 22 \\
00\end{array}$ & 10 \\
\hline 5 & $\begin{array}{l}\text { EVA32-b- } \\
\text { EVA03 }\end{array}$ & " & $\begin{array}{l}84 \mathrm{bar} ; 3.5 \mathrm{~mL} ; 16 \mathrm{mg} \\
1.2 \mathrm{~h}\end{array}$ & $0.34 \mathrm{~g}$ & $\begin{array}{l}4700 \mathrm{~g} \mathrm{~mol}^{-1} \\
(1.69) ; 10\end{array}$ & $\begin{array}{l}3300 / 22 \\
00\end{array}$ & 3 \\
\hline 6 & $\begin{array}{l}\text { PVAc- } b- \\
\text { EVA09 }\end{array}$ & $\begin{array}{l}1400 \mathrm{~g} \\
\mathrm{~mol}^{-1} \\
(1.29) ; 100\end{array}$ & $\begin{array}{l}75 \mathrm{bar} ; 7.5 \mathrm{~mL} ; 15 \mathrm{mg} \\
0.5 \mathrm{~h}\end{array}$ & $0.29 \mathrm{~g}$ & $\begin{array}{l}3700 \mathrm{~g} \mathrm{~mol}^{-1} \\
(1.90) ; 31\end{array}$ & $\begin{array}{l}3150 / 24 \\
00\end{array}$ & 9 \\
\hline 7 & $\begin{array}{l}\text { PVAc- } b- \\
\text { EVA10 }\end{array}$ & & $\begin{array}{l}75 \mathrm{bar} ; 7.5 \mathrm{~mL} ; 8 \mathrm{mg} \text {; } \\
0.7 \mathrm{~h}\end{array}$ & $0.43 \mathrm{~g}$ & $\begin{array}{l}7500 \mathrm{~g} \mathrm{~mol}^{-1} \\
(2.0) ; 20\end{array}$ & $\begin{array}{l}7200 / 44 \\
00\end{array}$ & 10 \\
\hline 8 & $\begin{array}{l}\text { PVAc- } b \text { - } \\
\text { EVA13 }\end{array}$ & $\begin{array}{l}800 \mathrm{~g} \mathrm{~mol}^{-1} \\
(1.38) ; 100\end{array}$ & $\begin{array}{l}75 \mathrm{bar} ; 7.5 \mathrm{~mL} ; 13 \mathrm{mg} \\
0.7 \mathrm{~h}\end{array}$ & $0.42 \mathrm{~g}$ & $\begin{array}{l}3000 \mathrm{~g} \mathrm{~mol}^{-1} \\
(2.1) ; 22\end{array}$ & $\begin{array}{l}2800 / 23 \\
00\end{array}$ & 13 \\
\hline
\end{tabular}

${ }^{a}$ Polymerization conditions: in an autoclave; in DMC, total volume (DMC and VAc) of $50 \mathrm{~mL}$; [macroCTA]:[AIBN] $=3: 1$; at $80{ }^{\circ} \mathrm{C}$. ${ }^{\mathrm{b}}$ Polymerization systems presented in the Supporting Information. ${ }^{\mathrm{C}} \mathrm{In} \mathrm{TCB}$ at $150{ }^{\circ} \mathrm{C}$ for entry 1 , in THF at $35^{\circ} \mathrm{C}$ for all other entries. ${ }^{\mathrm{d}, \mathrm{e}}$ From ${ }^{1} \mathrm{H}$ NMR spectroscopy. ${ }^{\mathrm{f}}$ Calculated considering the VAc contents of the diblock and the first block. 


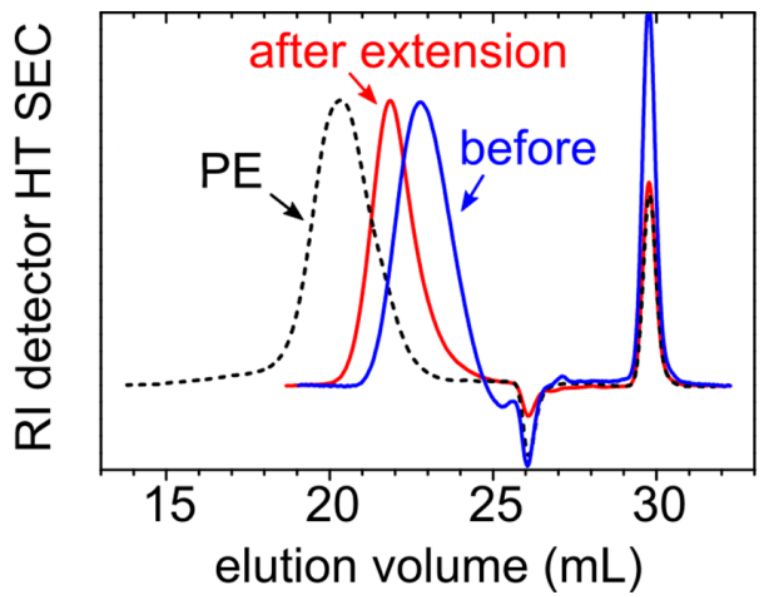

Figure 4. SEC traces of EVA22 (produced in the presence of DTC1) before and after extension with PE by RAFT (Table 2, entry 1) compared to PE produced from a conventional system. SEC analysis in TCB at $150{ }^{\circ} \mathrm{C}$.

${ }^{1} \mathrm{H}$ NMR spectra of EVA22 and EVA22-b-PE are presented in Figure 5. The signals are assigned as represented by the structural formula, including the monomer units of VAc (signals b-d) and E (signal e). Chain extension is supported by the transformation of signal f, corresponding to the $\mathrm{CH}_{2}$ protons adjacent to the $\mathrm{CS}_{2}$ unit. As the environment of the $\mathrm{CH}_{2}$ protons changes from an EVA with $22 \mathrm{~mol} \%$ of VAc to PE with $0 \mathrm{~mol} \%$ of VAc, signal $\mathrm{f}$ in Figure 5 transforms from a fairly distorted signal to a clean triplet consistently with what was mentioned above (Figure 3). Apart from chain extension, another triplet can be seen at about $2.4 \mathrm{ppm}$. This indicates the formation of a thioether species and a loss of chain-end functionality due to cross-termination events during the extension with $\mathrm{PE}$, as it was described earlier for xanthates and dithiocarbamates with aromatic Z-groups. ${ }^{27}$ The extent of supposed thioether formation can be obtained by comparing the corresponding signal at 2.4 ppm with the original signal at $3.2 \mathrm{ppm}$ of the $\mathrm{CH}_{2}$ adjacent to the $\mathrm{CS}_{2}$ unit. The calculation gives here $30 \%$ of RAFT groups transformed. It remains unclear at the moment why this side-reaction seems to be much more pronounced in chain extension than in the homopolymerization of E (cf. Figure 2a, about 5\% of RAFT groups transformed). In any way, the pronounced shift of the unimodal distribution in Figure 4 indicates a rapid and 
quantitative chain extension, so that it can be expected that this side reaction only occurs gradually during the polymerization.
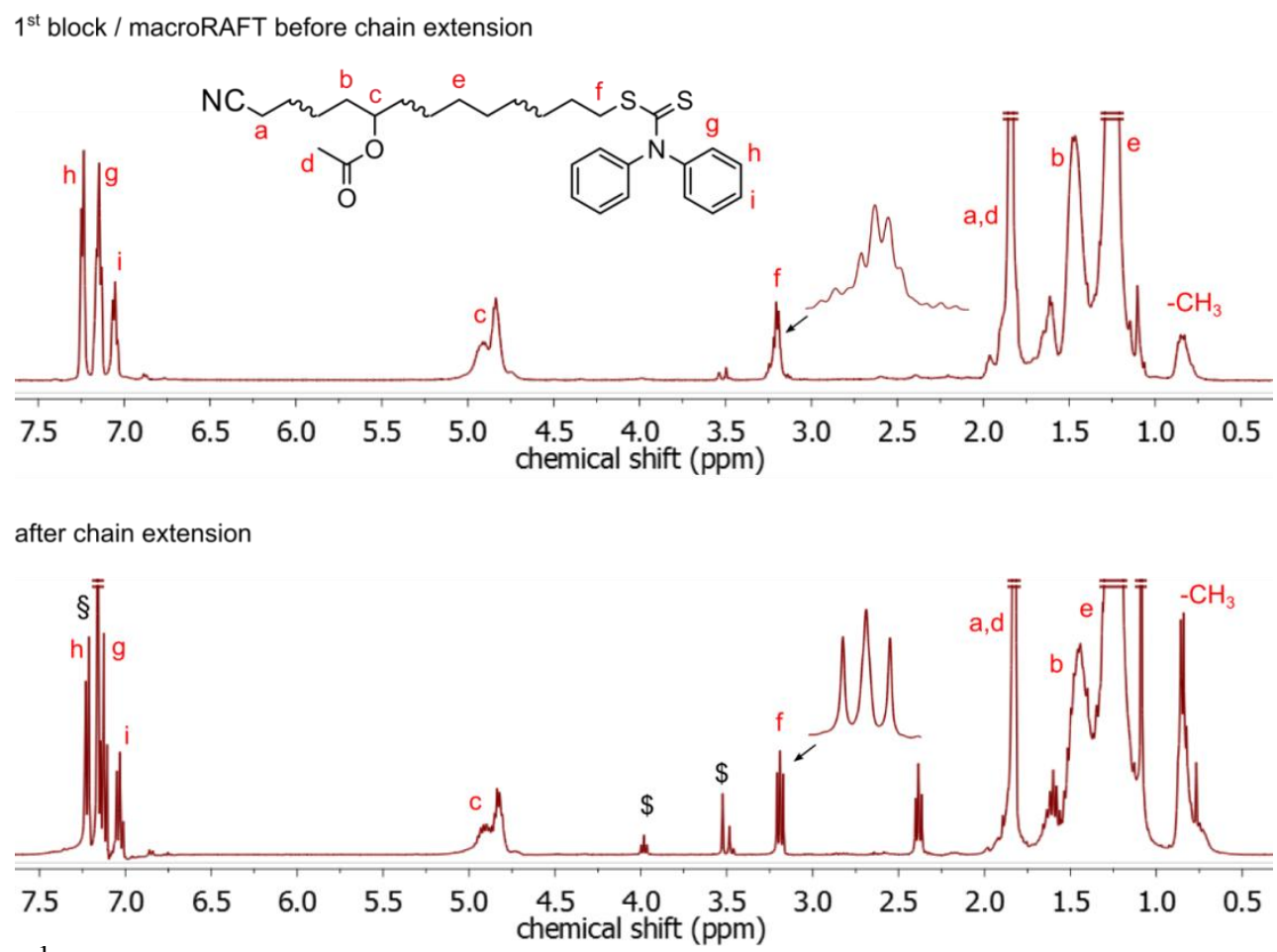

Figure 5. ${ }^{1} \mathrm{H}$ NMR spectra of EVA22 (synthesized in the presence of DTC1) before and after chain extension with PE to produce EVA22- $b$-PE (Table 2, entry 1). ${ }^{\S} \mathrm{NMR}$ solvent benzene, $\$$ transfer to polymerization solvent DMC.

\section{EVA-block-EVA}

Similar to EVA-b-PE, EVA- $b$-EVA copolymers were prepared by chain extensions of an EVA macroCTA synthesized in the presence of DTC1. In this context, two EVAs with about $20 \mathrm{~mol} \%$ and $30 \mathrm{~mol} \%$ of VAc were each extended with EVAs with about $10 \mathrm{~mol} \%$ and $5 \mathrm{~mol} \%$ of VAc. The resulting four different diblock copolymers are presented in Table 2 (entries 2 to 5). EVA- $b$-EVA like those produced here can be considered as simplified gradient copolymers, while the synthesis of copolymers with more than two blocks and more similar VAc contents would clearly lead to a smoother change of monomer composition along the chain. VAc contents of about $10 \mathrm{~mol} \%$ and $5 \mathrm{~mol} \%$ were targeted for the second block by selecting E pressures and VAc volumes for which EVAs with the corresponding 
VAc contents were obtained in previous polymerizations. The actual VAc contents of the second blocks were calculated considering the VAc contents of the diblock and the first block. They are close to the targeted ones (see last column of the Table 2). For all four diblock copolymers, NMR and SEC data indicated successful chain extension. This is elaborated below using the example of EVA32-b-EVA03 (entry 5), while the spectral data of the other diblock copolymers are presented in the Supporting Information. Figure 6 displays the ${ }^{1} \mathrm{H}$ NMR spectra of EVA32 (before extension) and EVA32- $b$-EVA03 (after extension). As observed before, the originally distorted signal $\mathrm{f}$ of the $\mathrm{CH}_{2}$ protons next to the $\mathrm{CS}_{2}$ unit is transformed to an almost clean triplet, indicating the change of these protons from an environment with a high amount of VAc (EVA32) to a low amount (EVA03). As before, but less intense than for the extension with PE (cf. Figure 5), a triplet can be detected at $2.4 \mathrm{ppm}$ indicating cross-termination events. Interestingly, while about $11 \%$ of RAFT groups are transformed for EVA32- $b$-EVA03, only 7\% are transformed for EVA32- $b$-EVA10. With $<2 \%$, even fewer RAFT groups are transformed for the macroRAFT EVA32. Since all three polymerization systems have comparable monomer conversions (EVA32-b-EVA05: $0.34 \mathrm{~g}$, EVA32-b-EVA10: $0.32 \mathrm{~g}$, EVA32: $0.58 \mathrm{~g}$ ) and it was found that cross-termination is proportional to monomer conversion, ${ }^{27}$ this suggests that cross-termination may be less pronounced for polymers with higher VAc contents. 
$1^{\text {st }}$ block / macroRAFT before chain extension

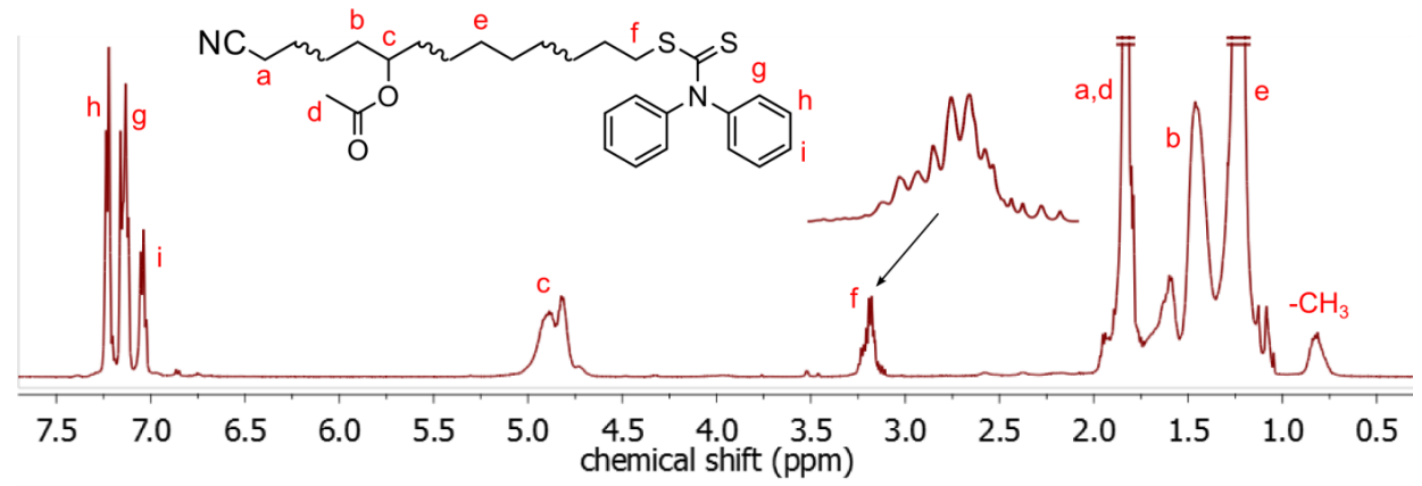

after chain extension

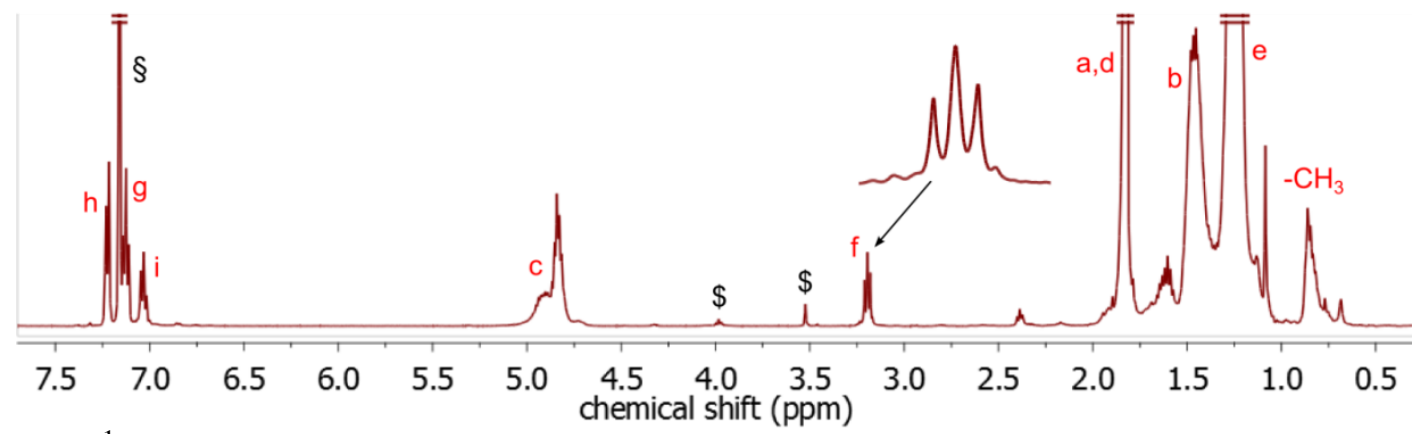

Figure 6. ${ }^{1} \mathrm{H}$ NMR spectra of EVA32 (synthesized in the presence of DTC1) before and after chain extension with EVA03 to produce EVA32-b-EVA03 (Table 2, entry 5). ${ }^{\S} \mathrm{NMR}$ solvent benzene, ${ }^{\$}$ transfer to polymerization solvent DMC.

Figure 7 shows the expected shift of SEC traces of EVA32 to EVA32- $b$-EVA03 for a successful chain extension. In addition to a refractive index (RI) detector, the SEC setup used for the EVA- $b$-EVA copolymers was also equipped with a UV detector-in contrast to the high-temperature SEC setup used for copolymers with a higher E content (cf. Figure 4). The signal from the UV detector at $300 \mathrm{~nm}$, which is within the typical absorption wavelength of dithiocarbonyl functions, extends over the entire chain distribution. This confirms that EVA32- $b$-EVA03 carries RAFT groups, as is expected for successful chain extension. 


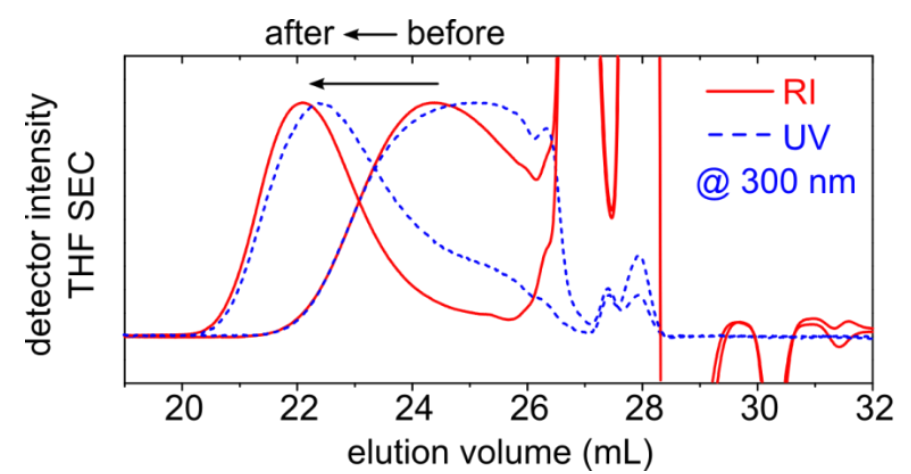

Figure 7. SEC traces of EVA32 (produced in the presence of DTC1) before and after extension with EVA03 by RAFT to produce EVA32- $b$-EVA03 (Table 2, entry 5). The unbroken line reflects the refractive index (RI) detector and the broken line to the UV detector at a wavelength of $300 \mathrm{~nm}$ (corresponding to the absorption of the thiocarbonyl function of the RAFT group). In THF at $35^{\circ} \mathrm{C}$.

\section{PVAc-block-EVA}

Three different PVAc- $b$-EVA copolymers were targeted from a PVAc macroCTA synthesized in the presence of DTC1. These include one PVAc- $b$-EVA synthesized from a shorter PVAc macroCTA (Table 2, entry 8) and two PVAc- $b$-EVA with different EVA molar masses synthesized from a higher molar mass PVAc macroCTA (entries 6 and 7). For all three diblock copolymers, NMR and SEC data indicated successful chain extension. As for the EVA- $b$-EVA copolymers, this is again elaborated using an example, namely the PVAc- $b$ EVA09 of entry 6, while the spectral data of the other polymers are given in the Supporting Information. Figure 8 shows the ${ }^{1} \mathrm{H}$ NMR spectra of PVAc (before extension) and PVAc- $b$ EVA09 (after extension). The protons of the VAc unit within the PVAc block of the polymer are represented by signals b-d and within the EVA09 block of the polymer by signals $\mathrm{i}-\mathrm{k}$. The protons of the $\mathrm{E}$ unit are represented by signal 1 . Before extension, the $\mathrm{CH}$ proton adjacent to the $\mathrm{CS}_{2}$ unit (signal e) is at about $6.8 \mathrm{ppm}$ without a significant amount of an inverse ultimate VAc unit $\left(\mathrm{CH}_{2}\right.$ protons from $3.6 \mathrm{ppm}$ to $3.1 \mathrm{ppm}$, cf. discussion based on Figure 2b). Chain extension at the polymer end is indicated by the change from signal e to signal $\mathrm{m}$, representing the $\mathrm{CH}_{2}$ protons adjacent to the $\mathrm{CS}_{2}$ unit in an EVA09 environment. 


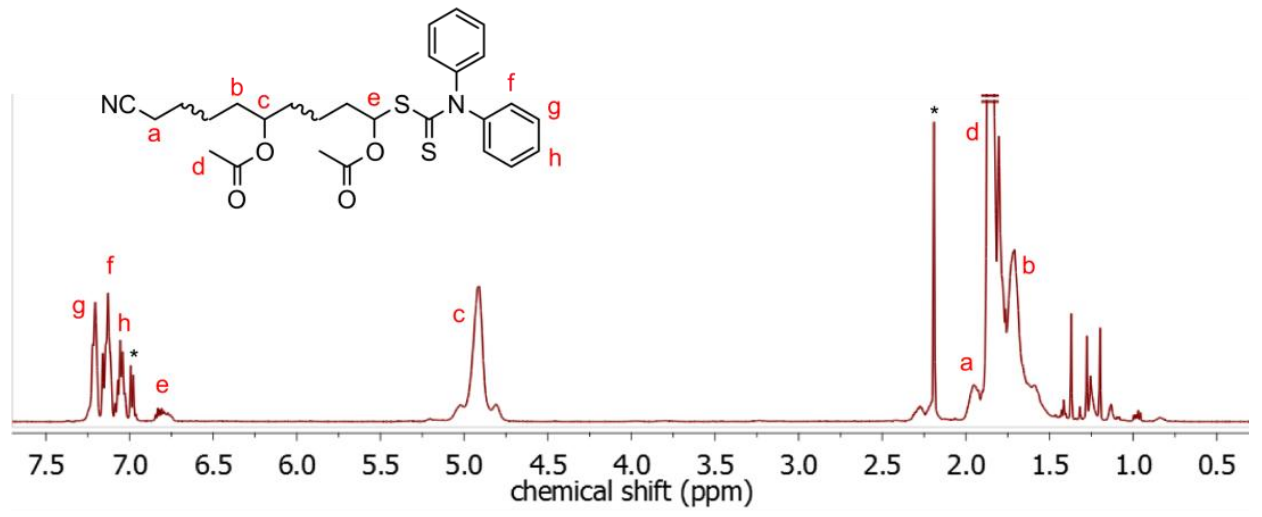

PVAc-b-EVA-RAFT species after chain extension

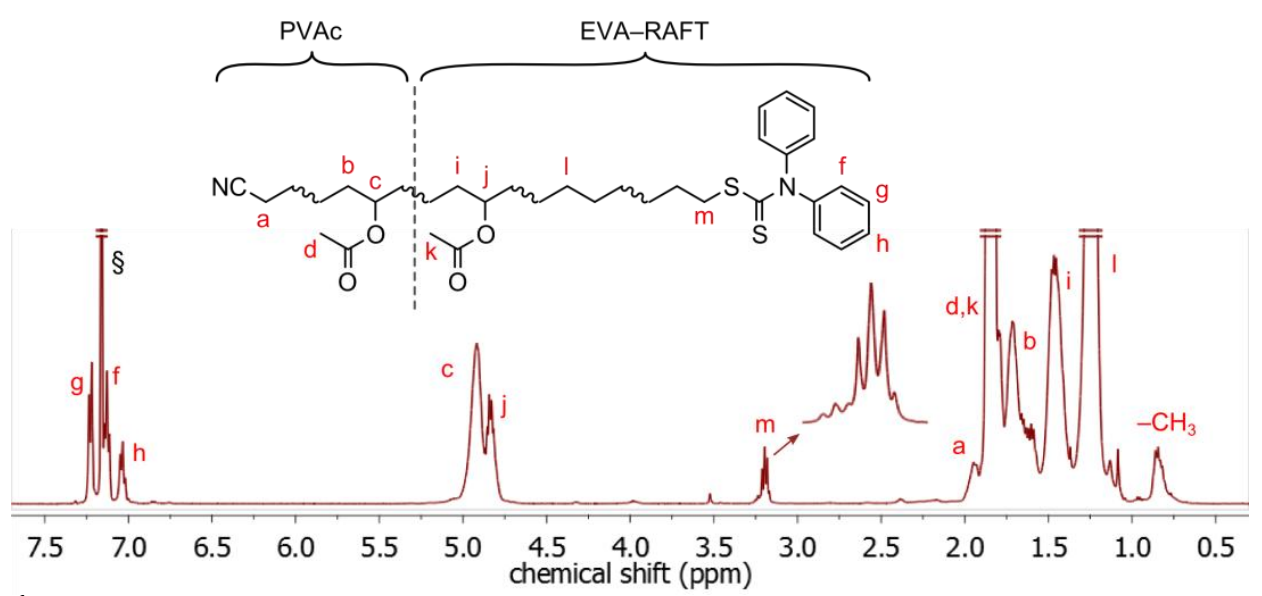

Figure 8. ${ }^{1} \mathrm{H}$ NMR spectra of PVAc (synthesized in the presence of DTC1) before and after chain extension with EVA09 to produce PVAc- $b$-EVA09 (Table 2, entry 6). ${ }^{\S} \mathrm{NMR}$ solvent benzene, *collecting solvent toluene.

Chain extension is indeed confirmed from inspection of the SEC traces of the PVAc and PVAc- $b$-EVA09 in Figure 9. Again, the signal of the UV detector shows the absorption of the dithiocarbamate group over the entire chain distributions of both PVAc and PVAc- $b$ EVA09. The same observation can be made for the other two types of PVAc- $b$-EVA. Naturally, the distributions before and after chain extension are better separated in case of the extension with the longer EVA block (entry 7). 


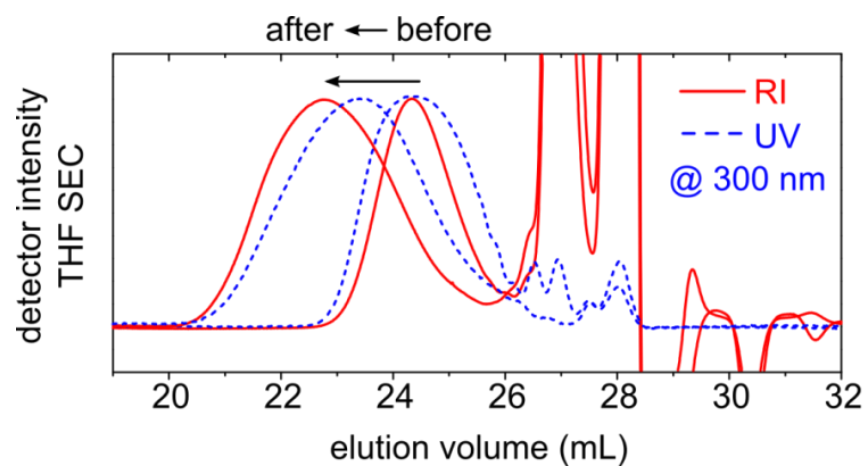

Figure 9. SEC traces of PVAc (produced in the presence of DTC1) before and after extension with EVA09 by RAFT to produce PVAc- $b$-EVA09 (Table 2, entry 6). The unbroken line reflects the refractive index (RI) detector and the broken line to the UV detector at a wavelength of $300 \mathrm{~nm}$ (corresponding to the absorption of the thiocarbonyl function of the RAFT group). In THF at $35^{\circ} \mathrm{C}$.

\section{Three-arm EVA star}

Three-arm star polymers have already been obtained by RAFT polymerization of VAc to further target three-arm star poly(vinyl alcohol) after hydrolysis. ${ }^{32,36}$ However, as far as we know, there is no example of EVA star copolymers produced by RAFT or any other polymerization technique. We hereby present the synthesis of a three-arm EVA star from a trifunctional dithiocarbamate CTA 3F-DTC (for structure see Scheme 1). The star was synthesized in a core-first R-group approach, i.e., the RAFT functionalities in 3F-DTC are attached to the core through their R-groups rather than their Z-groups. 3F-DTC was synthesized from a trifunctional bromo compound and a potassium dithiocarbamate salt $\mathbf{K}$ DTC as outlined in Scheme $1 .{ }^{37}$ Further details on the synthesis of both K-DTC and 3F-DTC are presented in the Supporting Information. It was preferred to synthesize a trifunctional CTA with the Z-groups $\mathrm{N}\left(\mathrm{CH}_{3}\right) \mathrm{Ph}$ (as DTC2) rather than $\mathrm{NPh}_{2}$ (as DTC1), although slower (re)initiation is expected. The reason for this is that in our hands the synthesis was regarded to be much more straightforward. Instead of a potassium salt, the synthesis of a trifunctional CTA with $\mathrm{Z}=\mathrm{NPh}_{2}$ requires a more reactive lithium salt and even then is less efficient. In addition, the lithium salt itself can only be synthesized in low yields and is air-sensitive and difficult to separate from the by-products formed. ${ }^{30}$ 
<smiles>BrCc1cc(CBr)cc(CBr)c1</smiles>
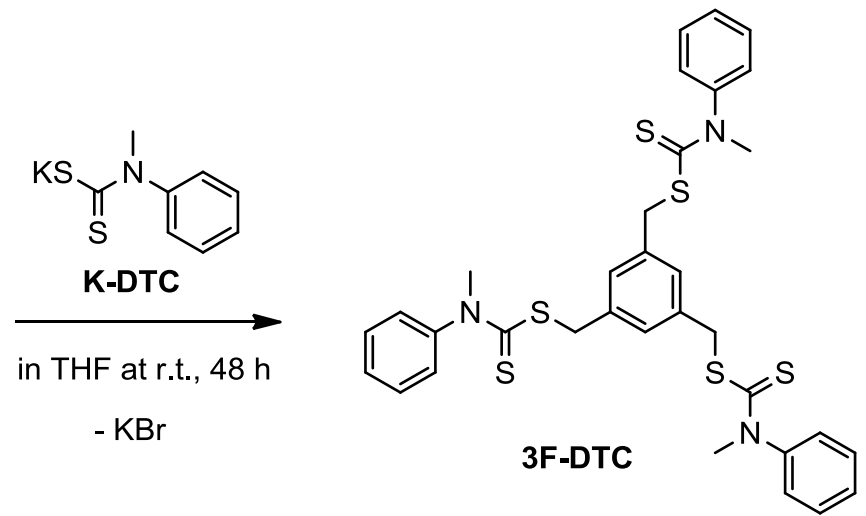

Scheme 1: Synthesis of the trifunctional RAFT agent 3F-DTC: reaction of tris(bromomethyl)benzene with the dithiocarbamate salt K-DTC.

Table 3. Results of the RAFT polymerization producing a three-arme EVA14 star in the presence of the trifunctional CTA 3F-DTC. ${ }^{\text {a }}$

\begin{tabular}{llllll}
\hline polymer type & $\begin{array}{l}\text { polymerizatio } \\
\text { n time }\end{array}$ & $\begin{array}{l}\text { monomer } \\
\text { conversion } \\
{[\mathrm{g}]}\end{array}$ & $\begin{array}{l}\text { VAc } \\
\text { content } \\
{[\mathrm{mol} \%]^{\mathrm{b}}}\end{array}$ & $\begin{array}{l}M_{\mathrm{n}}\left[\mathrm{g} \mathrm{mol}^{-1}\right](\bigoplus) \\
\operatorname{via~SEC~}^{\mathrm{c}}\end{array}$ & $\begin{array}{l}M_{\mathrm{n}, \text { theo }}^{\mathrm{d}}[\mathrm{g} \\
\left.\mathrm{mol}^{-1}\right]^{\mathrm{c}}\end{array}$ \\
\hline three-arm & $1.5 \mathrm{~h}$ & 0.57 & 14 & $6600(2.3)$ & 5400 \\
EVA14 star & & & &
\end{tabular}

${ }^{\text {a}}$ Polymerization conditions: in an autoclave, 75 bar of $\mathrm{E}$ pressure, $7.5 \mathrm{~mL}$ of VAc, [3FDTC]:[AIBN] = 1:1 (corresponding to [RAFT functionalities]:[AIBN] $=3: 1,20 \mathrm{mg}$ of AIBN, solvent DMC to a total volume of $50 \mathrm{~mL}, 80{ }^{\circ} \mathrm{C}$. ${ }^{\mathrm{b}}$ From ${ }^{1} \mathrm{H}$ NMR spectroscopy. ${ }^{\mathrm{c}} \mathrm{In}$ $\mathrm{THF}$ at $35^{\circ} \mathrm{C}$ (equivalents of polystyrene). ${ }^{\mathrm{d}} M_{\mathrm{n}, \text { theo }}=$ monomer conversion (both $\mathrm{E}$ and VAc, in $\mathrm{g}$ ) / amount of 3F-DTC (in mol) $\times 3+M_{3 \text { F-DTC }}\left(\right.$ in $\mathrm{g} \mathrm{mol}^{-1}$ ).

The polymerization conditions and the results are presented in Table 3. The ${ }^{1} \mathrm{H}$ NMR spectra of (a) the trifunctional bromo precursor, (b) 3F-DTC, and (c) the EVA produced in its presence are shown in Figure 10. The quantitative conversion of the bromo to dithiocarbamate functions can be seen from the disappearance of the signals $a$ and $b$ and the appearance of signals $\mathrm{c}$ and $\mathrm{d}$ in the targeted 3F-DTC. While the generation of EVA is obvious from signals $\mathrm{j}-\mathrm{m}$, the typical signal of the EVA's ultimate $\mathrm{CH}_{2}$ group adjacent to the $\mathrm{CS}_{2}$ functions can be seen at $3.2 \mathrm{ppm}$ (signal $\mathrm{n}$ ). This supports the participation of the RAFT functionalities during polymerization and the successful formation of a three-arm EVA star. By comparing the intensities of signals $\mathrm{c}$ and e (of remaining 3F-DTC) with those of signals 
$\mathrm{h}$ and $\mathrm{n}$ (of the three-arm star) in Figure 10c, it can be concluded that $92 \%$ of the original RAFT functionalities have already (re)initiated new chains at the end of polymerization.

(a) trifunctional precursor

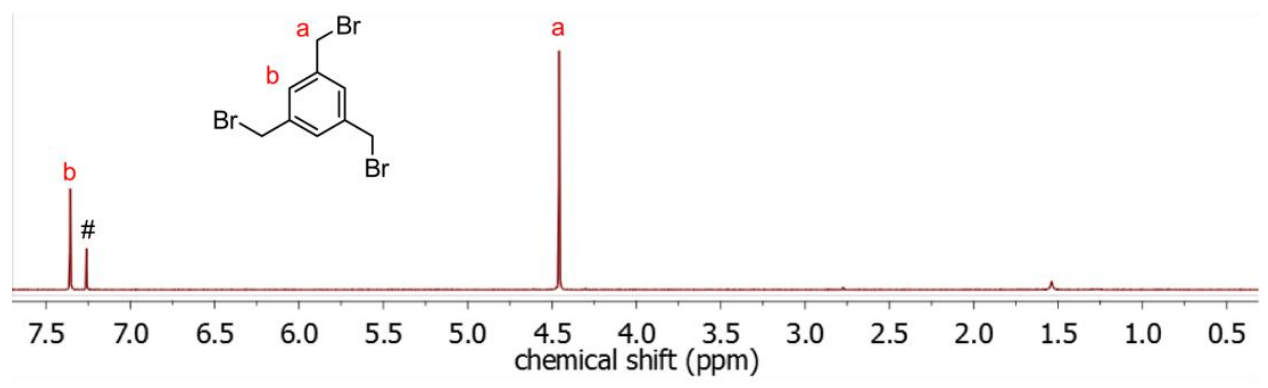

(b) trifunctional RAFT agent

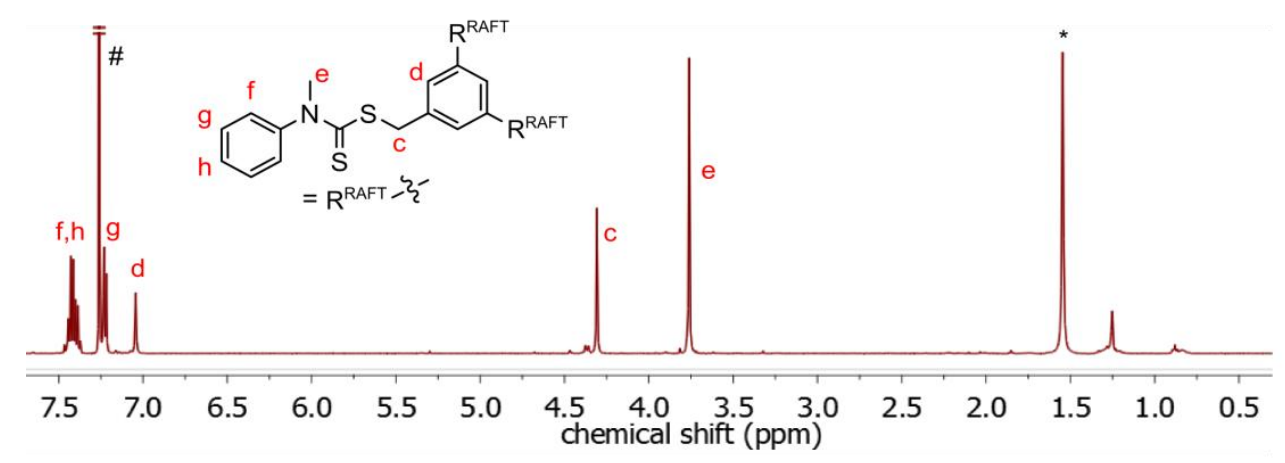

(c) three-armed EVA star

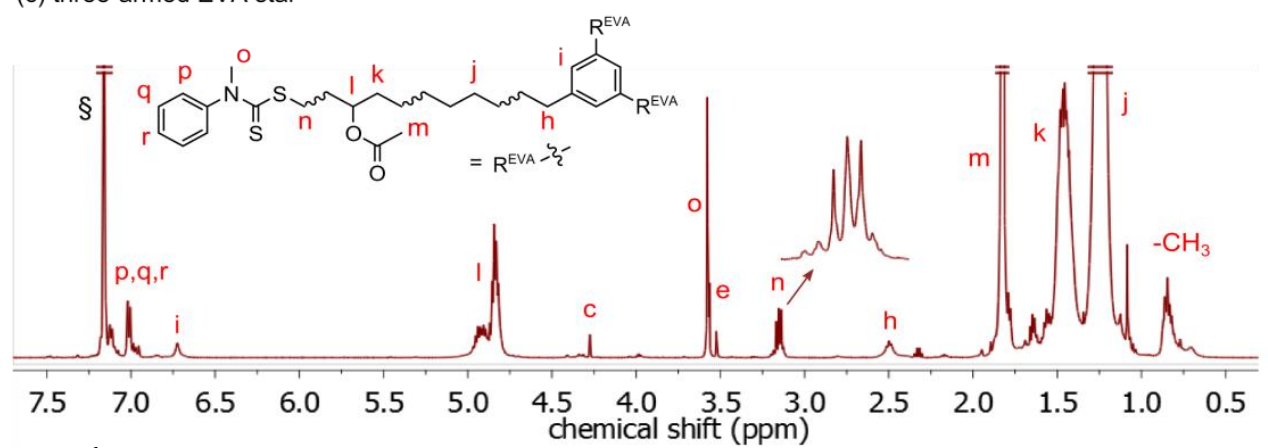

Figure 10. ${ }^{1} \mathrm{H}$ NMR spectra of (a) the trifunctional precursor tris(bromomethyl)benzene, (b) the trifunctional RAFT agent 3F-DTC, and (c) the three-arm EVA star. *Water. NMR solvents ${ }^{\#} \mathrm{CDCl}_{3}$ and ${ }^{\S}$ benzene. Spectra (a) and (b) recorded in $\mathrm{CDCl}_{3}$ at ambient temperature, spectrum $(\mathrm{c})$ recorded in TCE/benzene $=2: 1$ in volume at $90{ }^{\circ} \mathrm{C}$.

The SEC trace of the three-arm EVA star is presented in Figure 11. It is recorded with both an RI and a UV detector at $300 \mathrm{~nm}$. The UV signal spans well over the entire RI signal of the 
chain distribution. This further supports the functionalization of the EVA chains and a successful synthesis of the three-arm EVA star.
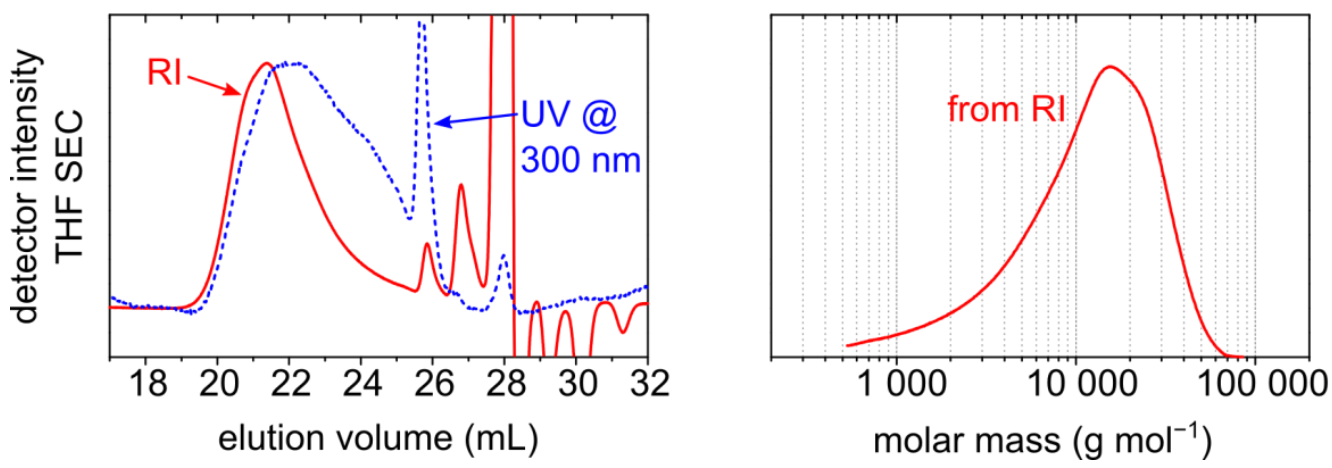

Figure 11. Left: SEC traces of the three-arm EVA star (cf. Table 3) recorded with an RI and with a UV detector at $300 \mathrm{~nm}$. Right: Corresponding MMD obtained from a conventional calibration with PS.

\section{Conclusion}

DTC1 was established as a powerful CTA for the synthesis of statistical and diblock copolymers of E and VAc by RAFT. In this context, DTC1 was shown to control chain growth of PE, PVAc, and EVA with high chain-end fidelity as attested by NMR analysis. Diblock copolymers of the type EVA- $b$-PE, EVA- $b$-EVA, and PVAc- $b$-EVA were successfully synthesized. In addition, the use of the trifunctional dithiocarbamate 3F-DTC offered a possibility to synthesize an original three-arm EVA star.

\section{Acknowledgements}

Drs. Maria Rappo and Ana-Maria Cenacchi Pereira (Total Marketing Services, Solaize, France) are acknowledged for fruitful discussions and Total Marketing Services for fundings. Dr. Cédric Bergerbit is acknowledged for fruitful discussions on the synthesis of the trifunctional RAFT agent. This article is a tribute to the $50^{\text {th }}$ anniversary of the French Polymer Group (Groupe Français des Polymères - GFP). 


\section{References}

(1) Henderson, A. M. Ethylene-Vinyl Acetate (EVA) Copolymers: A General Review. IEEE Electrical Insulation Magazine 1993, 9 (1), 30-38. https://doi.org/10.1109/57.249923.

(2) Scott, P. J.; Penlidis, A.; Rempel, G. L. Ethylene-Vinyl Acetate Semi-Batch Emulsion Copolymerization: Experimental Design and Preliminary Screening Experiments. Journal of Polymer Science Part A: Polymer Chemistry 1993, 31 (2), 403-426. https://doi.org/10.1002/pola.1993.080310213.

(3) Fink, J. K. Ethylene Vinyl Acetate Copolymers. In Handbook of Engineering and Specialty Thermoplastics; John Wiley \& Sons, Ltd, 2010; pp 187-209. https://doi.org/10.1002/9780470881712.ch7.

(4) Zarrouki, A.; Espinosa, E.; Boisson, C.; Monteil, V. Free Radical Copolymerization of Ethylene with Vinyl Acetate under Mild Conditions. Macromolecules 2017, 50 (9), 3516-3523. https://doi.org/10.1021/acs.macromol.6b02756.

(5) Schneider, C.; Langer, R.; Loveday, D.; Hair, D. Applications of Ethylene Vinyl Acetate Copolymers (EVA) in Drug Delivery Systems. J Control Release 2017, 262, 284-295. https://doi.org/10.1016/j.jconrel.2017.08.004.

(6) Reyes, J. D. Innovative Uses of Ethylene Vinyl Acetate Polymers for Advancing Healthcare. In SPE Polyolefins Conference; 2014.

(7) Maes, C.; Luyten, W.; Herremans, G.; Peeters, R.; Carleer, R.; Buntinx, M. Recent Updates on the Barrier Properties of Ethylene Vinyl Alcohol Copolymer (EVOH): A Review. Polymer Reviews 2018, $58 \quad$ (2), 209-246. https://doi.org/10.1080/15583724.2017.1394323.

(8) Frauendorfer, E.; Babar, M.; Melchin, T.; Hergeth, W.-D. Monitoring of Vinyl AcetateEthylene Processes: An Industrial Perspective. In Polymer Reaction Engineering of Dispersed Systems: Volume II; Pauer, W., Ed.; Advances in Polymer Science; Springer International Publishing: Cham, 2018; pp 183-214. https://doi.org/10.1007/12_2017_22.

(9) Corrigan, N.; Jung, K.; Moad, G.; Hawker, C. J.; Matyjaszewski, K.; Boyer, C. Reversible-Deactivation Radical Polymerization (Controlled/Living Radical Polymerization): From Discovery to Materials Design and Applications. Progress in Polymer Science 2020, $111, \quad 101311$. https://doi.org/10.1016/j.progpolymsci.2020.101311.

(10) Destarac, M. Industrial Development of Reversible-Deactivation Radical Polymerization: Is the Induction Period Over? Polym. Chem. 2018, 9 (40), 4947-4967. https://doi.org/10.1039/C8PY00970H.

(11) Benaglia, M.; Chiefari, J.; Chong, Y. K.; Moad, G.; Rizzardo, E.; Thang, S. H. Universal (Switchable) RAFT Agents. J. Am. Chem. Soc. 2009, 131 (20), 6914-6915. https://doi.org/10.1021/ja901955n.

(12) Dommanget, C.; D’Agosto, F.; Monteil, V. Polymerization of Ethylene through Reversible Addition-Fragmentation Chain Transfer (RAFT). Angewandte Chemie International Edition 2014, 53 (26), 6683-6686. https://doi.org/10.1002/anie.201403491.

(13) Harrisson, S.; Liu, X.; Ollagnier, J.-N.; Coutelier, O.; Marty, J.-D.; Destarac, M. RAFT Polymerization of Vinyl Esters: Synthesis and Applications. Polymers 2014, 6 (5), 1437-1488. https://doi.org/10.3390/polym6051437.

(14) Yamago, S.; Iida, K.; Yoshida, J. Tailored Synthesis of Structurally Defined Polymers by Organotellurium-Mediated Living Radical Polymerization (TERP): Synthesis of Poly(Meth)Acrylate Derivatives and Their Di- and Triblock Copolymers. J. Am. Chem. Soc. 2002, 124 (46), 13666-13667. https://doi.org/10.1021/ja027599i. 
(15) Yamago, S. Precision Polymer Synthesis by Degenerative Transfer Controlled/Living Radical Polymerization Using Organotellurium, Organostibine, and Organobismuthine Chain-Transfer Agents. Chem. Rev. 2009, 109 (11), 5051-5068. https://doi.org/10.1021/cr9001269.

(16) Debuigne, A.; Caille, J.-R.; Jérôme, R. Highly Efficient Cobalt-Mediated Radical Polymerization of Vinyl Acetate. Angewandte Chemie International Edition 2005, 44 (7), 1101-1104. https://doi.org/10.1002/anie.200461333.

(17) Iovu, M. C.; Matyjaszewski, K. Controlled/Living Radical Polymerization of Vinyl Acetate by Degenerative Transfer with Alkyl Iodides. Macromolecules 2003, 36 (25), 9346-9354. https://doi.org/10.1021/ma034892+.

(18) Borkar, S.; Sen, A. Controlled Copolymerization of Vinyl Acetate with 1-Alkenes and Their Fluoro Derivatives by Degenerative Transfer. Journal of Polymer Science Part A: Polymer Chemistry 2005, 43 (17), 3728-3736. https://doi.org/10.1002/pola.20802.

(19) Bryaskova, R.; Willet, N.; Degée, P.; Dubois, P.; Jérôme, R.; Detrembleur, C. Copolymerization of Vinyl Acetate with 1-Octene and Ethylene by Cobalt-Mediated Radical Polymerization. Journal of Polymer Science Part A: Polymer Chemistry 2007, 45 (12), 2532-2542. https://doi.org/10.1002/pola.21963.

(20) Kermagoret, A.; Debuigne, A.; Jérôme, C.; Detrembleur, C. Precision Design of Ethylene- and Polar-Monomer-Based Copolymers by Organometallic-Mediated Radical Polymerization. Nat Chem 2014, 6 (3), 179-187. https://doi.org/10.1038/nchem.1850.

(21) Demarteau, J.; Scholten, P. B. V.; Kermagoret, A.; De Winter, J.; Meier, M. A. R.; Monteil, V.; Debuigne, A.; Detrembleur, C. Functional Polyethylene (PE) and PE-Based Block Copolymers by Organometallic-Mediated Radical Polymerization. $\begin{array}{lllll}\text { Macromolecules } & \mathbf{2 0 1 9}, & 52 & \text { (22), }\end{array}$ https://doi.org/10.1021/acs.macromol.9b01741.

(22) Demarteau, J.; Winter, J. D.; Detrembleur, C.; Debuigne, A. Ethylene/Vinyl AcetateBased Macrocycles via Organometallic-Mediated Radical Polymerization and CuAAC 'Click' Reaction. Polym. Chem. 2018, 9 (3), 273-278. https://doi.org/10.1039/C7PY01891F.

(23) Demarteau, J.; Kermagoret, A.; Jérôme, C.; Detrembleur, C.; Debuigne, A. Controlled Synthesis of Ethylene-Vinyl Acetate Based Copolymers by Organometallic Mediated Radical Polymerization. In Controlled Radical Polymerization: Materials; ACS Symposium Series; American Chemical Society, 2015; Vol. 1188, pp 47-61. https://doi.org/10.1021/bk-2015-1188.ch004.

(24) Zeng, T.; You, W.; Chen, G.; Nie, X.; Zhang, Z.; Xia, L.; Hong, C.; Chen, C.; You, Y. Degradable PE-Based Copolymer with Controlled Ester Structure Incorporation by Cobalt-Mediated Radical Copolymerization under Mild Condition. iScience 2020, 23 (3). https://doi.org/10.1016/j.isci.2020.100904.

(25) Grau, E.; Broyer, J.-P.; Boisson, C.; Spitz, R.; Monteil, V. Free Ethylene Radical Polymerization under Mild Conditions: The Impact of the Solvent. Macromolecules 2009, 42 (19), 7279-7281. https://doi.org/10.1021/ma901622u.

(26) Nakamura, Y.; Ebeling, B.; Wolpers, A.; Monteil, V.; D’Agosto, F.; Yamago, S. Controlled Radical Polymerization of Ethylene Using Organotellurium Compounds. Angewandte Chemie International Edition 2018, 57 (1), 305-309. https://doi.org/10.1002/anie.201709946.

(27) Wolpers, A.; Bergerbit, C.; Ebeling, B.; D’Agosto, F.; Monteil, V. Aromatic Xanthates and Dithiocarbamates for the Polymerization of Ethylene through Reversible AdditionFragmentation Chain Transfer (RAFT). Angewandte Chemie International Edition 2019, 58 (40), 14295-14302. https://doi.org/10.1002/anie.201905629. 
(28) Wolpers, A.; Baffie, F.; Verrieux, L.; Perrin, L.; Monteil, V.; D’Agosto, F. IodineTransfer Polymerization (ITP) of Ethylene and Copolymerization with Vinyl Acetate. Angewandte Chemie International Edition 2020, 59 (43), 19304-19310. https://doi.org/10.1002/anie.202008872.

(29) Zeng, T.-Y.; Xia, L.; Zhang, Z.; Hong, C.-Y.; You, Y.-Z. Dithiocarbamate-Mediated Controlled Copolymerization of Ethylene with Cyclic Ketene Acetals towards Polyethylene-Based Degradable Copolymers. Polym. Chem. 2021, 12 (2), 165-171. https://doi.org/10.1039/D0PY00200C.

(30) Bergerbit, C.; Baffie, F.; Wolpers, A.; Dugas, P.-Y.; Boyron, O.; Taam, M.; Lansalot, M.; Monteil, V.; D'Agosto, F. Ethylene Polymerization-Induced Self-Assembly (PISA) of Poly(Ethylene Oxide)-Block-Polyethylene Copolymers via RAFT. Angewandte Chemie International Edition 2020, 59 (26), 10385-10390. https://doi.org/10.1002/anie.202001741.

(31) Góis, J. R.; Popov, A. V.; Guliashvili, T.; Serra, A. C.; Coelho, J. F. J. Synthesis of Functionalized Poly(Vinyl Acetate) Mediated by Alkyne-Terminated RAFT Agents. RSC Adv. 2015, 5 (111), 91225-91234. https://doi.org/10.1039/C5RA15580K.

(32) Stenzel, M. H.; Davis, T. P.; Barner-Kowollik, C. Poly(Vinyl Alcohol) Star Polymers Prepared via MADIX/RAFT Polymerisation. Chem. Commun. 2004, No. 13, 15461547. https://doi.org/10.1039/B404763J.

(33) Guerre, M.; Semsarilar, M.; Godiard, F.; Améduri, B.; Ladmiral, V. PolymerizationInduced Self-Assembly of PVAc-b-PVDF Block Copolymers via RAFT Dispersion Polymerization of Vinylidene Fluoride in Dimethyl Carbonate. Polym. Chem. 2017, 8 (9), 1477-1487. https://doi.org/10.1039/C6PY02203K.

(34) Guerre, M.; Rahaman, S. M. W.; Améduri, B.; Poli, R.; Ladmiral, V. RAFT Synthesis of Well-Defined PVDF-b-PVAc Block Copolymers. Polym. Chem. 2016, 7 (45), 69186933. https://doi.org/10.1039/C6PY01247G.

(35) De Rybel, N.; Van Steenberge, P. H. M.; Reyniers, M.-F.; D’hooge, D. R.; Marin, G. B. Interplay of Head, Tail, and Mid-Chain Radicals in Bulk Free-Radical and Reversible Degenerative Addition Fragmentation Chain-Transfer Polymerizations of Vinyl Acetate. Macromolecules $\quad 2019, \quad 52 \quad$ (12), https://doi.org/10.1021/acs.macromol.9b00762.

(36) Bernard, J.; Favier, A.; Zhang, L.; Nilasaroya, A.; Davis, T. P.; Barner-Kowollik, C.; Stenzel, M. H. Poly(Vinyl Ester) Star Polymers via Xanthate-Mediated Living Radical Polymerization: From Poly(Vinyl Alcohol) to Glycopolymer Stars. Macromolecules 2005, 38 (13), 5475-5484. https://doi.org/10.1021/ma050050u.

(37) Grigoras, M.; Negru, O.-I. Synthesis of Star Poly(N-Vinylcarbazole) by MicrowaveAssisted Reversible Addition-Fragmentation Chain Transfer Polymerization (RAFT). Polymers 2012, 4 (2), 1183-1194. https://doi.org/10.3390/polym4021183. 